\section{Colour and achromatic perimetry in diabetic children without retinopathy}

Dear Sir,

Increasing interest has been given to the use of colour perimetry $[1,2]$ and some authors have demonstrated that blue-onyellow perimetry is more sensitive than achromatic perimetry in demonstrating subtle visual defects not found with achromatic perimetry $[1,3,4]$. We evaluated blue-on-yellow perimetry to compare the results with achromatic perimetry and to establish whether colour perimetry could be useful to detect functional impairment in a diabetic population with persistent microalbuminuria.

We studied 50 children and adolescents (22 male, 28 female mean age $13.3 \pm 2.1$ years) with insulin-dependent diabetes mellitus with mean disease duration of $7.1 \pm 1.9$ years and with glycated haemoglobin $\left(\mathrm{HbA}_{1 \mathrm{c}}\right)$ values ranging from 6.0 to $8.4 \%$. All patients selected for the study had the following characteristics: glycaemic control evaluated by $\mathrm{HbA}_{1 \mathrm{c}}$ less than $9 \%$; glycaemic values ranging from 4.9 to $6.9 \mathrm{mmol} / \mathrm{l}$ before the functional examination; clear optic media; no fluorescein angiographic signs of retinopathy. Fifty healthy age and sex-matched subjects served as a control group.

All patients underwent the following monocular examinations, testing the right eye first (100 eyes): chromatic sense (Farnsworth 100 HUE, KOCCMORGEN CORPORATION, Baltimore, MD, USA) with evaluation of 'total error score' and central static automated perimetry (in all patients pupil size was greater than $3 \mathrm{~mm}$ ), performed with both achromatic and blue-on-yellow stimuli.

The patients were divided in subgroups according to the presence of persistent microalbuminuria (defined as albumin excretion rate $(A E R)>20 \mu \mathrm{g} / \mathrm{min}$ in at least six urine examinations, carried out every 2 months in the last year before the beginning of the study): group $\mathrm{A}$, microalbuminuric patients, 10 male and 12 female, and group B, normoalbuminuric patients, 12 male and 16 female. Mean AER in group A was $35.19 \pm 13.93 \mu \mathrm{g} \cdot \mathrm{min}^{-1} \cdot 1.73 \mathrm{~m}^{-2}$ (range $22.1-78.2$ ) and in group B $9.0 \pm 4.77 \mu \mathrm{g} \cdot \mathrm{min}^{-1} \cdot 1.73 \mathrm{~m}^{-2}$ (range 3.2-19.1). Group $\mathrm{A}$ and $\mathrm{B}$ were similar for disease duration and quality of metabolic control evaluated by $\mathrm{HbA}_{1 \mathrm{c}}$. $\mathrm{HbA}_{1 \mathrm{c}}$ in groups $\mathrm{A}$ and $B$ was $7.4 \pm 2.1$ and $7.9 \pm 2.5 \%$, respectively.

Static perimetry was performed with a modified Humphrey Perimeter model 640 (Humphrey Instruments, San Leandro, Calif., USA), using the 24-2 program. We evaluated only right eyes. Evaluated visual field parameters was the mean sensitiv- ity both for achromatic and blue-on-yellow perimetry. The modifications for blue-on-yellow perimetry became operative after the instrument had performed its standard internal calibration routine. Background illumination was extinguished using standard Humphrey software. To produce the background a carousel projector was mounted on the left side of the perimeter cabinet [3]. The differences in mean sensitivity for each group under each test condition (achromatic and colour perimetry) were evaluated.

Statistical analysis was performed with SPSS software package (Release 6.0; Chicago, Ill., USA). A normal distribution of data was found in both groups for each test. Intergroup analysis was performed with one-way analysis of variance (ANOVA). Linear regression analysis was used to evaluate the relationship between microalbuminuria and perimetric sensitivity. The level of significance was set at $p<0.05$.

No significant differences between mean total error scores of diabetic subgroups (group A: $109.27 \pm 53.41$ - group B: $105.947 \pm 52.38)$ and control subjects $(98.54 \pm 37.70)$ were found. Achromatic perimetry showed mean perimetric sensitivity similar in diabetic subgroups and control subjects (Table 1). On the contrary, microalbuminuric patients showed lower values of the mean perimetric sensitivity than normoalbuminuric patients $(p<0.00001)$ and control subjects $(p<0.00001)$ (Table 1).

Regression analysis showed a significant relation between the AER and the retinal differential sensitivity between blueon-yellow and achromatic perimetry $(p=0.0008)$.

Our data suggest that diabetic children without fluorescein angiographic signs of retinopathy can have an impairment of achromatic and chromatic perimetry if they present persistent microalbuminuria. This observation is in agreement with data of other authors, who detected impairment in psychophysical tests in the absence of fluorescein angiographic signs of retinopathy [5-7]. Moreover, our study provides evidence that, although no significant difference between diabetic subgroups was found as regards central colour vision, blue-on-yellow perimetry shows perimetric defects not detected by achromatic perimetry. Colour perimetry seems to be more useful than achromatic perimetry in the detection of retinal impairment in diabetic microalbuminuric patients without fluorescein angiographic signs of retinopathy. The significant correlation between the AER and the retinal differential sensitivity between blue-on-yellow and achromatic perimetry indirectly confirms this usefulness. This study is in agreement with previous reports $[3,8,9]$ suggesting that colour perimetry is more useful and more sensitive than achromatic perimetry in the detection of preclinical visual defects in various diseases affecting the

Table 1. Foveal threshold and mean sensitivity in the central 30 degrees tested with achromatic and blue-on-yellow perimetry in diabetic subgroups and control subjects

\begin{tabular}{|c|c|c|c|c|}
\hline \multirow{2}{*}{$\begin{array}{l}\text { Diabetic } \\
\text { patients }\end{array}$} & \multicolumn{2}{|c|}{ Foveal threshold (db) } & \multicolumn{2}{|c|}{ Mean sensitivity $(\mathrm{db})$} \\
\hline & achromatic & blue-on-yellow & achromatic & blue-on-yellow \\
\hline $\begin{array}{l}\text { Microalbuminuric patients } \\
\text { (Group A) }\end{array}$ & $32.75 \pm 1.61$ & $21.18 \pm 1.67$ & $29.14 \pm 2.09$ & $17.14 \pm 1.62^{\mathrm{a}, \mathrm{b}}$ \\
\hline $\begin{array}{l}\text { Normoalbuminuric patients } \\
\text { (Group B) }\end{array}$ & $32.89 \pm 1.93$ & $21.57 \pm 1.54$ & $29.95 \pm 2.19$ & $19.55 \pm 1.89$ \\
\hline Control subjects & $33.04 \pm 2.03$ & $21.69 \pm 1.42$ & $30.27 \pm 4.45$ & $19.70 \pm 1.75$ \\
\hline
\end{tabular}

${ }^{\mathrm{a}}$ Compared to normoalbuminuric patients $p<0.00001 ;{ }^{\mathrm{b}}$ compared to control subjects $p<0.00001$

Corresponding author: L. Lobefalo, M. D., v. Gran Sasso 100, I-

66100 Chieti, Italy 
central visual field. To the best of our knowledge, this is the first study that has been performed with blue-on-yellow perimetry in diabetic children: our study has shown that in diabetic children with persistent microalbuminuria, the visual field defects are more severe than hitherto thought; in fact, by means of colour perimetry, it is possible to detect a significant reduction. As it stands the results seem to be of preliminary nature but point to the possibility that careful analysis by means of blue-on-yellow perimetry will detect young patients at risk of developing early visual defects.

Yours sincerely,

L. Lobefalo, A. Verrotti, L. Mastropasqua, F. Chiarelli, G. Della

Loggia, G. Morgese, P.E. Gallenga

\section{References}

1. Heron G, Adams AJ, Husted R (1988) Central visual fields for short wave-length sensitive pathway in glaucoma and ocular hypertension. Invest Ophthalmol Vis Sci 29: 64-72

2. Vingrys AJ, King-Smith PE, Benes SC (1989) Color perimetry can be more sensitive than achromatic perimetry. Clin Vis Sci 4: 197-209
3. Sample PA, Weinreb RN (1990) Color perimetry for assessment of primary open-angle glaucoma. Invest Ophthalmol Vis Sci 31: 1869-1875

4. Sample PA, Taylor JDN, Martinez GA, Lusky M, Weinreb RN (1993) Short-wavelength color visual fields in glaucoma suspect at risk. Am J Ophthalmol 115: 225-233

5. Mastropasqua L, Verrotti A, Lobefalo L, Chiarelli F, Verdesca G, Morgese G (1995) Visual field defects in diabetic children without microalbuminuria. Acta Ophthalmol 73: $125-128$

6. Greenstein V, Sarter B, Hood D, Noble K, Carr R (1990) Hue discrimination and $\mathrm{S}$ cone pathway sensitivity in early diabetic retinopathy. Invest Ophthalmol Vis Sci 31: 10081014

7. Kurtenbach A, Wagner U, Neu A, Schiefer U, Ranke MB, Zrenner E (1993) Brightness matching and colour discrimination in young diabetics without retinopathy. Vision Res 34: $115-122$

8. De Jong LAMS, Felius J, Van Der Berg TJTP, Greve EL (1992) Use of blue filter in visual field analysis. Br J Ophthalmol 76: 447-448

9. Hart WM, Silverman SE, Trick GL, Nesher R, Gordon MO (1990) Glaucomatous visual field damage. Luminance and color contrast sensitivities. Invest Ophthalmol Vis Sci 31: 359-367 